\title{
Effect of intranasal esketamine on cognitive functioning in healthy participants: a randomized, double-blind, placebo-controlled study
}

\author{
Randall L. Morrison ${ }^{1,2} \cdot$ Maggie Fedgchin ${ }^{2} \cdot$ Jaskaran Singh $^{2} \cdot$ Joop Van Gerven ${ }^{3} \cdot$ Rob Zuiker $^{3} \cdot$ Kyoung Soo Lim ${ }^{3,4}$. \\ Peter van der Ark ${ }^{5}$. Ewa Wajs ${ }^{5}$. Liwen $\mathrm{Xi}^{2} \cdot$ Peter Zannikos $^{2}$. Wayne C. Drevets ${ }^{2}$
}

Received: 18 May 2017 / Accepted: 3 January 2018 / Published online: 1 February 2018

(C) The Author(s) 2018. This article is an open access publication

\begin{abstract} (29.2\%), and fatigue (29.2\%); the majority were considered mild in severity.

Trial registration: ClinicalTrials.gov identifier: NCT02094378

Previous presentation: These data have been presented as a poster at the 54th Annual Meeting of the American College of

Neuropsychopharmacology (ACNP), December 6-10, 2015, Hollywood, FL, and at the Society of Biological Psychiatry (SOBP), May 12-14, 2016, Atlanta, GA.
\end{abstract}

Background The effect of intranasal esketamine on cognitive functioning in healthy participants is assessed in this study. Methods Twenty-four participants (19-49 years) were randomized to one of two treatment sequences in which either esketamine $84 \mathrm{mg}$ or placebo was intranasally administered in a double-blind, two-period crossover design. Primary measures included five tests of Cogstate ${ }^{\circledR}$ computerized test battery assessed at $1 \mathrm{~h}$ predose and $40 \mathrm{~min}, 2,4$, and $6 \mathrm{~h}$ postdose. Secondary measures included the Mental Effort Scale, Karolinska Sleepiness Scale (KSS), and safety.

Results Esketamine was associated with significant cognitive performance impairment at 40 min postdose for all five Cogstate ${ }^{\circledR}$ tests (Detection $p=0.0011$, Identification $p=0.0006$, One-Card Learning $p=0.0040$, One Back $p=0.0017$, and Groton Maze Learning Test $p<0.0001$ ) versus placebo. In contrast, performance on these tests did not differ significantly between esketamine and placebo at 2, 4, or $6 \mathrm{~h}$ postdose. Secondary outcomes indicated a significant, transient increase from baseline under esketamine versus placebo at $40 \mathrm{~min}$ postdose on the Mental Effort Scale and at $40 \mathrm{~min}$ and $2 \mathrm{~h}$ postdose on KSS $(p<0.0001$ for both); however, no significant difference was observed on these outcomes between esketamine and placebo at later timepoints. The most commonly reported adverse events were dizziness (67\%), nausea (37.5\%), disturbance in attention

Conclusions Esketamine was associated with cognitive performance decline, and greater effort was required to complete the test battery versus placebo at $40 \mathrm{~min}$ postdose, which returned to placebo-comparable levels by $2 \mathrm{~h}$ postdose.

Electronic supplementary material The online version of this article (https://doi.org/10.1007/s00213-018-4828-5) contains supplementary material, which is available to authorized users.

Randall L. Morrison

rmorris5@its.jnj.com

1 Neuroscience Integrative Solutions, 1125 Trenton-Harbourton Road, Titusville, NJ 08560, USA

2 Janssen Research \& Development, LLC, Titusville, NJ, USA

3 Centre for Human Drug Research, Leiden, The Netherlands

4 CHA University School of Medicine and CHA Budang Medical Center, Seongnam, South Korea

5 Janssen Research \& Development, a Division of Janssen Pharmaceutica NV, Beerse, Belgium
Keywords Cognitive functioning $\cdot$ Cogstate ${ }^{\circledR}$ computerized test battery $\cdot$ Intranasal esketamine $\cdot$ Treatment-resistant depression

\section{Introduction}

Major depressive disorder (MDD) is a leading cause of disability worldwide and the most common antecedent illness to suicide (WHO Fact Sheet, reviewed April 2016). Although many psychopharmacological agents are currently available for the treatment of MDD, a substantial proportion of patients with MDD are resistant to conventional monoaminergic antidepressants and more effective interventions are needed for treatment-resistant depression (TRD). Additionally, patients who do respond to currently approved antidepressants require up to 4-6 weeks to show any improvement (Machado-Vieira et al. 2009).

Ketamine, an N-methyl-D-aspartate (NMDA) receptor antagonist, has been reported to exert a rapid onset of antidepressant effect in patients with TRD (Newport et al. 2015). 
Intranasal ketamine has shown safety and efficacy as an anesthetic and analgesic agent (Weksler et al. 1993; Louon and Reddy 1994; Diaz 1997; Weber et al. 2003). Intravenous ketamine has shown impairing effects on cognitive performance parameters that typically peak following administration and resolve within a few minutes to up to $2 \mathrm{~h}$ after drug discontinuation (Mathew et al. 2010; Murrough et al. 2013a, b; Zarate et al. 2006).

Several studies have examined cognitive function in infrequent and frequent ketamine users (Narendran et al. 2005; Morgan and Curran 2006; Morgan et al. 2009). Overall, infrequent or recreational ketamine use does not appear to be associated with long-term cognitive impairment (Narendran et al. 2005). In contrast, frequent ketamine users (more than five times per week) exhibit impairments in both short- and long-term memory (Morgan and Curran 2006). Although dosages used have varied, the doses reported by frequent ketamine users in this study were much higher than the doses that have been reported in the literature to alleviate depression severity in TRD (Newport et al. 2015) and usually used in combination with other drugs. Memory impairments may be reversible when individuals stop using the drug, as they were not found in a group of 30 former ketamine users who had been abstinent for at least one year (Morgan et al. 2010).

Esketamine (JNJ54135419), the S-enantiomer of ketamine racemate, has three to four times higher affinity for NMDA receptors than the R-enantiomer (Himmelseher and Pfenninger 1998), allowing antidepressant efficacy at lower doses (Singh et al. 2016). The intranasal route of administration is generally more convenient than intravenous delivery and also circumvents the relatively poor bioavailability associated with the oral route of administration for ketamine and esketamine. The relatively rapid onset of action and increased bioavailability of the drug administered via the intranasal delivery route are attributable to the rich vasculature and relatively high systemic absorption of esketamine via the nasal mucosa (Andrade 2015). The absolute bioavailability of intranasal esketamine $20 \mathrm{mg}$ and $25 \mathrm{mg}$ in healthy participants ranged between 45 and 59\% (Bitter 2011; Yanagihara et al. 2003).

In healthy participants, intranasal esketamine has been relatively well-tolerated (Bitter 2011). However, the potential effects of intranasal esketamine on cognitive functioning have not been studied previously. Here, we evaluate the magnitude and duration of effects on cognitive function of a single dose of intranasal esketamine $84 \mathrm{mg}$ in healthy volunteers.

\section{Methods}

\section{Study population}

Healthy men and women aged 19 to 49 years, with a body mass index 18 to $30 \mathrm{~kg} / \mathrm{m}^{2}$ and a body weight of no less than $45 \mathrm{~kg}$, were recruited into the study. Participants were excluded if they had systolic blood pressure measurements less than $90 \mathrm{mmHg}$ or greater than $140 \mathrm{mmHg}$, diastolic blood pressure higher than $90 \mathrm{mmHg}$, or clinically significant abnormalities on electrocardiogram. Participants were also excluded if they had clinically significant medical conditions (including primary sleep disorder), abnormal laboratory values or abnormal physical/nasal examination, current or prior diagnosis of psychosis/psychotic disorder, or performance greater than one standard deviation (SD) below the mean on any of the five tests of the Cogstate ${ }^{\circledR}$ computerized test battery during the training session.

\section{Study design}

This phase 1, double-blind (DB), randomized, placebo-controlled, two-period crossover study was conducted at a single center in the Netherlands from June 2014 to August 2014 (NCT02094378).

The study consisted of three phases: screening phase (up to 3 weeks), DB treatment phase (2 weeks), and posttreatment (follow-up) phase (1 week). During the screening phase, evaluation of eligibility for participation included two training sessions on the Cogstate ${ }^{\circledR}$ computerized test battery. The DB treatment phase consisted of two treatment periods (periods 1 and 2) separated by a washout interval of at least 7 days. On day 1 of study period 1, participants were randomized to one of two treatment sequences (treatment sequence 1: intranasal esketamine $84 \mathrm{mg}$ followed by intranasal placebo; treatment sequence 2: intranasal placebo followed by intranasal esketamine $84 \mathrm{mg}$ ) in a two-way crossover design (Fig. 1). Randomization was based on a computergenerated randomization schedule prepared before the study by or under the supervision of the sponsor. The intranasal dose of esketamine $84 \mathrm{mg}$ was selected because it produced a pharmacokinetic profile similar to that of an intravenously administered esketamine dose of $0.2 \mathrm{mg} / \mathrm{kg}$, which showed antidepressant effects similar to higher doses of intravenous esketamine (Singh et al. 2016; Daly et al. 2017). The investigators, participants, and all study staff were kept blinded to the assigned treatment at randomization. Methylxanthinecontaining products (chocolate bars, beverages, coffee, teas, colas, alcohol, etc) were prohibited from $24 \mathrm{~h}$ prior to administration of study medication.

\section{Assessments}

\section{Cognitive functioning measures}

The primary endpoint was change in cognitive performance on each cognitive test from $1 \mathrm{~h}$ predose to each postdose timepoint on day $1(40 \mathrm{~min}, 2 \mathrm{~h}, 4 \mathrm{~h}$, and $6 \mathrm{~h}$ ) and at 2-h intervals until participants returned to predose cognitive 
Fig. 1 Study design and participant flow

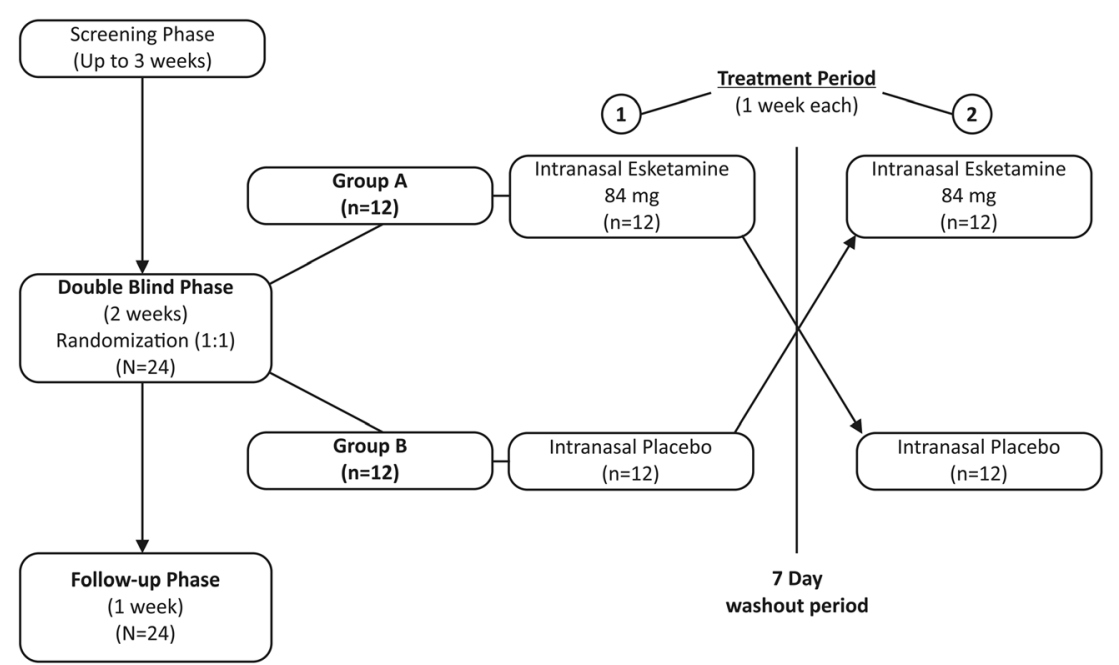

function for each treatment period. Using the Cogstate ${ }^{\circledR}$ computerized test battery, the study evaluated multiple cognitive domains, including attention, visual and working memory, and executive functioning. The Cogstate ${ }^{\circledR}$ computerized test battery consists of five tests/scores: Detection, Identification, One-Card Learning, One Back Memory, and Groton Maze Learning. The tests use playing card stimuli and a maze task, enabling use in multilingual/multicultural settings. Each test has been utilized in earlier drug studies, and the sensitivity of the Cogstate battery has been validated across repeated testing and cross-sectional research designs (Olver et al. 2008; Yoshida et al. 2012; McIntyre et al. 2014; Shiroma et al. 2014). The difference in each participant's performance on any cognitive measure from predose was based on the Reliable Change Index (RCI), with an absolute value of $\mathrm{RCI} \geq 1.96$ considered to be a meaningful change from the predose score for a test. Participants whose performance on any cognitive test had not returned to predose performance level by $6 \mathrm{~h}$ postdose continued cognitive testing at 2-h intervals until all test scores had returned to predose levels. The criterion for continued testing was any cognitive test score that in comparison to the predose score fell in a range defined by the absolute value of $|\mathrm{RCI}| \geq 1.96$ (i.e., $\mathrm{RCI} \leq-1.96$ or $\mathrm{RCI} \geq 1.96$ ). The secondary endpoints were the level of effort needed to complete the Cogstate ${ }^{\circledR}$ computerized test battery and the level of sleepiness, as assessed by the change from baseline to each postdose timepoint on day 1 (40 $\mathrm{min}, 2 \mathrm{~h}, 4 \mathrm{~h}$, and $6 \mathrm{~h}$ ) for each treatment period using the Mental Effort Scale and the Karolinska Sleepiness Scale (KSS), respectively.

\section{Safety and tolerability}

Safety was evaluated by recording treatment-emergent adverse events (TEAEs), laboratory tests, vital signs, physical examinations, electrocardiogram monitoring, Columbia Suicide Severity Rating Scale (C-SSRS), Modified
Observer's Assessment of Alertness/Sedation (MOAA/S), Brief Psychiatric Rating Scale (BPRS+), and Clinician Administered Dissociative States Scale (CADSS). Additionally, local nasal tolerability was assessed by the nasal tolerability questionnaire and nasal examination.

\section{Statistical methods}

\section{Sample size determination}

The sample size was prespecified to 24 participants. Assuming $80 \%$ of power and a two-sided significance level of 0.05 , with a sample size of 24 participants, the study was able to detect the minimal detectable differences between esketamine and placebo in each cognitive test: Detection: 0.04, Identification: 0.04, One-Card Learning: 0.08, One Back: 0.15, and Groton Maze Learning Test: 12.87; assuming within-participant SDs $0.06,0.07,0.13,0.25$, and 21.5 for the aforementioned five tests obtained from the healthy control group $(n=120)$ in a study comparing the Cogstate ${ }^{\circledR}$ battery and the Measurement and Treatment Research to Improve Cognition in Schizophrenia (MATRICS) battery (Pietrzak et al. 2009). A mixed-effect analysis of variance (ANOVA) model was used to assess the treatment difference in terms of five tests of the Cogstate ${ }^{\circledR}$ Computerized Test Battery. The units for these tests are the mean of $\log 10$ transformed reaction times for correct responses $(\log 10 \mathrm{~ms})$ on Detection and Identification tests, arcsine transformation of the proportion of correct responses for the One-Card Learning test, speed of performance ( $\log 10$ $\mathrm{ms}$ ) for the One Back Test, and total number of errors committed for the Groton Maze Learning Test.

\section{Analysis set}

The intent-to-treat (ITT) or safety analysis set included all randomized participants who received at least one dose of study medication during the DB phase. 


\section{Statistical analyses}

Statistical analyses were performed using $\mathrm{SAS}^{\circledR}$ version 9.2. A mixed-effect analysis of variance (ANOVA) model was applied to each of the five tests of the Cogstate ${ }^{\circledR}$ Computerized Test Battery to estimate treatment differences for each timepoint. The model included treatment, period, gender, and sequence as fixed effects and participants within sequence as a random effect. Baseline measures of scores were added as a covariate to the mixed-effect analysis of variance model. For this primary analysis (i.e., five Cogstate ${ }^{\circledR}$ tests at $40 \mathrm{~min}$ ), the Hochberg procedure was utilized to control the family-wise error rate. In addition, for assessing the learning effect, screening period versus period 1 predose and screening period versus period 2 predose were examined for the five Cogstate ${ }^{\circledR}$ tests using paired $t$ tests. To assess sex effects, a mixed-effect model was applied using repeated measures (MMRM) with baseline as a covariate, the period, sequence, time, sex and sex-by-time interaction as fixed effects, and the subject as a random effect for each of the five Cogstate $^{\circledR}$ tests. Mental Effort Scale and KSS were analyzed using the aforementioned mixed-effect model for the primary analysis. The incidence of adverse events was summarized by treatment group.

\section{Results}

\section{Participants}

All 24 enrolled and randomized participants completed the study. The demographics and baseline characteristics were comparable across the groups assigned to treatment sequence A versus B (Table 1).

\section{Cognitive function measures}

\section{Primary cognitive function measures}

Compared to predose assessments, cognitive performance declined to a greater extent under intranasal esketamine $84 \mathrm{mg}$ than under placebo on each test at $40 \mathrm{~min}$ postdose (Table 2). At the 40 min postdose assessment, significant differences in the least squares (LS) mean (SE) values for the five Cogstate ${ }^{\circledR}$ tests were noted for placebo versus esketamine (Fig. 2). The cognitive function in participants receiving esketamine returned to levels comparable to placebo by $2 \mathrm{~h}$ postdose. When comparing the two treatment groups, there was no significant difference between esketamine $84 \mathrm{mg}$ and placebo in performance on any cognitive test at the 2-, 4-, or 6-h postdose assessments. A total of seven participants (esketamine: $n=4$, placebo: $n=3$ ) had $|\mathrm{RCI}| \leq-1.96$ on at least one cognitive test at $6 \mathrm{~h}$ post-treatment, whereas a total of 25 participants (esketamine: $n=14$, placebo: $n=11$ ) met the criteria for continued testing of $\mathrm{RCI} \geq 1.96$ on at least one test $6 \mathrm{~h}$ post-treatment. Several participants continued to exhibit performance on a cognitive test that differed from predose performance through $10 \mathrm{~h}$ post esketamine or placebo, such that four who received esketamine and two who received placebo continued to perform below baseline (i.e., $\mathrm{RCI}<-1.96$ ), while ten who received esketamine and four who received placebo performed better than baseline ( $\mathrm{RCI} \geq 1.96$; see Online Resource, supplementary Tables 1 and 2).
Table 1 Demographic and baseline characteristics

\begin{tabular}{|c|c|c|}
\hline & $\begin{array}{l}\text { Treatment sequence } 1^{\mathrm{a}} \\
n=12\end{array}$ & $\begin{array}{l}\text { Treatment sequence } 2^{\mathrm{b}} \\
n=12\end{array}$ \\
\hline \multicolumn{3}{|l|}{ Age (years) } \\
\hline Mean (SD) & $23.7(8.07)$ & $27.0(7.86)$ \\
\hline \multicolumn{3}{|l|}{ Gender, $n(\%)$} \\
\hline Male & $6(50)$ & $6(50)$ \\
\hline \multicolumn{3}{|l|}{ Race, $n(\%)$} \\
\hline White & $11(92)$ & $11(92)$ \\
\hline Other & $1(8)$ & 0 \\
\hline Black or African American & 0 & $1(8)$ \\
\hline \multicolumn{3}{|l|}{ Ethnicity, $n(\%)$} \\
\hline Not Hispanic or Latino & $10(83)$ & $12(100)$ \\
\hline Hispanic or Latino & $2(17)$ & 0 \\
\hline \multicolumn{3}{|l|}{ BMI $\left(\mathrm{kg} / \mathrm{m}^{2}\right)$} \\
\hline Mean (SD) & $22.7(2.81)$ & $24.4(3.67)$ \\
\hline
\end{tabular}


Table 2 Cognitive Functioning Tests: LS Means (SE) Over Time

\begin{tabular}{|c|c|c|c|}
\hline & $\begin{array}{l}\text { Placebo } \\
(\mathrm{N}=24)\end{array}$ & $\begin{array}{l}\text { Esketamine } 84 \mathrm{mg} \\
(\mathrm{N}=23 / 24)^{\mathrm{a}}\end{array}$ & $p$ value $\mathrm{e}^{\mathrm{b}}$ \\
\hline \multicolumn{4}{|c|}{$\operatorname{Detection}^{\mathrm{c}}(\log 10 \mathrm{~ms})$} \\
\hline 40 minutes ${ }^{\mathrm{d}}$ & $2.44(0.014)$ & $2.51(0.014)$ & 0.0011 \\
\hline 2 hours & $2.42(0.011)$ & $2.43(0.011)$ & 0.8217 \\
\hline 4 hours & $2.43(0.011)$ & $2.41(0.011)$ & 0.3802 \\
\hline 6 hours & $2.43(0.013)$ & $2.40(0.013)$ & 0.1358 \\
\hline \multicolumn{4}{|c|}{ Identification $^{\mathrm{c}}(\log 10 \mathrm{~ms})$} \\
\hline 40 minutes & $2.64(0.009)$ & $2.68(0.009)$ & 0.0006 \\
\hline 2 hours & $2.63(0.010)$ & $2.63(0.010)$ & 0.7941 \\
\hline 4 hours & $2.63(0.009)$ & $2.62(0.009)$ & 0.2226 \\
\hline 6 hours & $2.63(0.011)$ & $2.60(0.011)$ & 0.1290 \\
\hline \multicolumn{4}{|c|}{ One-Card Learning (arcsine of proportion of correct responses) } \\
\hline 40 minutes & $1.09(0.021)$ & $0.99(0.021)$ & 0.0040 \\
\hline 2 hours & $1.11(0.021)$ & $1.07(0.021)$ & 0.1483 \\
\hline 4 hours & $1.12(0.021)$ & $1.10(0.021)$ & 0.4465 \\
\hline 6 hours & $1.15(0.017)$ & $1.15(0.017)$ & 0.7450 \\
\hline \multicolumn{4}{|c|}{ One Back Memory ${ }^{\mathrm{c}}$ (Log10 ms) } \\
\hline 40 minutes & $2.75(0.012)$ & $2.80(0.012)$ & 0.0017 \\
\hline 2 hours & $2.74(0.012)$ & $2.76(0.012)$ & 0.1579 \\
\hline 4 hours & $2.73(0.010)$ & $2.74(0.010)$ & 0.3791 \\
\hline 6 hours & $2.72(0.011)$ & $2.72(0.011)$ & 0.9674 \\
\hline \multicolumn{4}{|c|}{ Groton Maze Learning Test (total numbers of errors) } \\
\hline 40 minutes & $38.5(2.45)$ & $59.7(2.51)$ & $<0.0001$ \\
\hline 2 hours & $36.7(2.26)$ & $41.7(2.31)$ & 0.1250 \\
\hline 4 hours & $39.6(2.17)$ & $37.1(2.17)$ & 0.2986 \\
\hline 6 hours & $33.6(1.79)$ & $36.8(1.79)$ & 0.1422 \\
\hline
\end{tabular}

Detection - speed of performance ( $\log 10 \mathrm{~ms})$, Identification - speed of performance (Log $10 \mathrm{~ms}$ ), One-Card learning - accuracy of performance, One Back memory - speed of performance (Log10 ms), Groton Maze learning test - total numbers of errors, $\mathrm{ms}$ - milliseconds

${ }^{\mathrm{a}} \mathrm{N}=23$ in esketamine groups for 40 minutes and 2 hours testing periods, $\mathrm{N}=24$ for 4 and 6 hours testing periods

${ }^{\mathrm{b}} p$ values (2-sided with level of significance of $5 \%$ ) are based on the mixed-effect model with baseline score as a covariate, and treatment, period, gender and sequence as fixed effects, and subject within sequence as a random effect

${ }^{\mathrm{c}}$ For these timed tests, higher scores reflect poorer performance

${ }^{\mathrm{d}}$ All times listed (40 minutes, 2, 4, and 6 hours) reflect the times following dosing at which the testing was performed

In order to evaluate potential learning effects, subjects' performance on each test was evaluated across screening period versus period 1 predose and screening period versus period 2 predose. There was no significant difference in performance on cognitive tests between screening period versus period 1 predose (Table 3). There were differences for three tests-Detection (simple reaction time task appears to be longer at predose period 2 than that at screening period; LS mean difference $=0.089$ and $p=0.006<0.05$ ),
Groton Maze Learning (total number of errors appears to be smaller at predose period 2 than that at screening period; LS mean difference $=-5.500$ and $p=0.010<0.05$ ), and Identification (choice reaction time paradigm appears to be longer at predose period 2 than that at screening period; LS mean difference $=0.065$ and $p=0.003<0.05$ ) between the screening period and period 2 pre-dose (Table 3 ). There were significant differences on performance at the screening period versus period 2 predose for Detection $(p<0.01)$, Groton Maze Learning $(p=0.01)$, and Identification $(p<0.01)$. With respect to gender, a significant difference was found in One-Card Learning at $40 \mathrm{~min}$ in the placebo group, but performance did not differ significantly between males and females in the other tests (Supplementary Table 3).

\section{Secondary cognitive function measures}

\section{Mental Effort Scale}

Greater effort was required to complete the cognitive test battery after receiving esketamine versus placebo at the first postdose time point only (40 min postdose). Mental Effort Scale LS mean (SE) values at $40 \mathrm{~min}$ postdose were placebo: $2.74(0.35)$ versus esketamine: $7.01(0.358), p<0.0001$. Higher scores indicate greater mental effort required. The mental effort required to perform the cognitive tests returned to levels comparable to placebo by $2 \mathrm{~h}$ postdose (Fig. 3a), as the differences between esketamine versus placebo at the 2-, 4-, and 6-h postdose assessments were not statistically significant.

\section{Karolinska Sleepiness Scale}

Increased sleepiness was observed after esketamine administration compared to placebo, with significant differences between groups observed in the KSS at $40 \mathrm{~min}$ and $2 \mathrm{~h}$ postdose, returning to comparable levels as placebo by $4 \mathrm{~h}$ postdose. The KSS LS mean (SE) values (placebo versus esketamine) at 40 min postdose were $3.85(0.344)$ versus $6.32(0.344)$, $p<0.0001$; at $2 \mathrm{~h}$ postdose: $3.53(0.270)$ versus 5.46 (0.283), $p<0.0001$; and at $4 \mathrm{~h}$ postdose: $4.14(0.261)$ versus 4.27 (0.261), $p=0.72$ (Fig. 3b).

\section{Safety}

The most frequently reported TEAEs after intranasal esketamine administration included dizziness $(n=16$, $67 \%)$, nausea $(n=9,38 \%)$, disturbance in attention, fatigue and somnolence ( $n=7,29 \%$ each), and feeling abnormal $(n=6,25 \%)$ (Table 4). The majority of TEAEs reported were rated as mild or moderate in intensity, and all TEAEs resolved at the end of the study. No deaths or other serious 
a

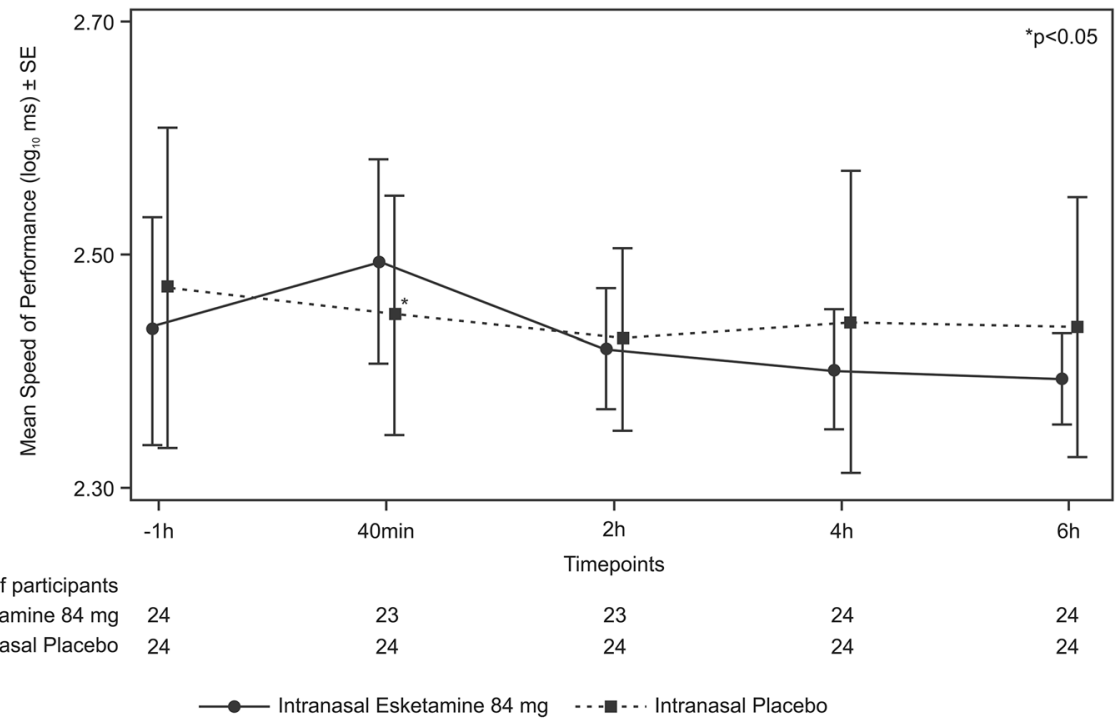

b

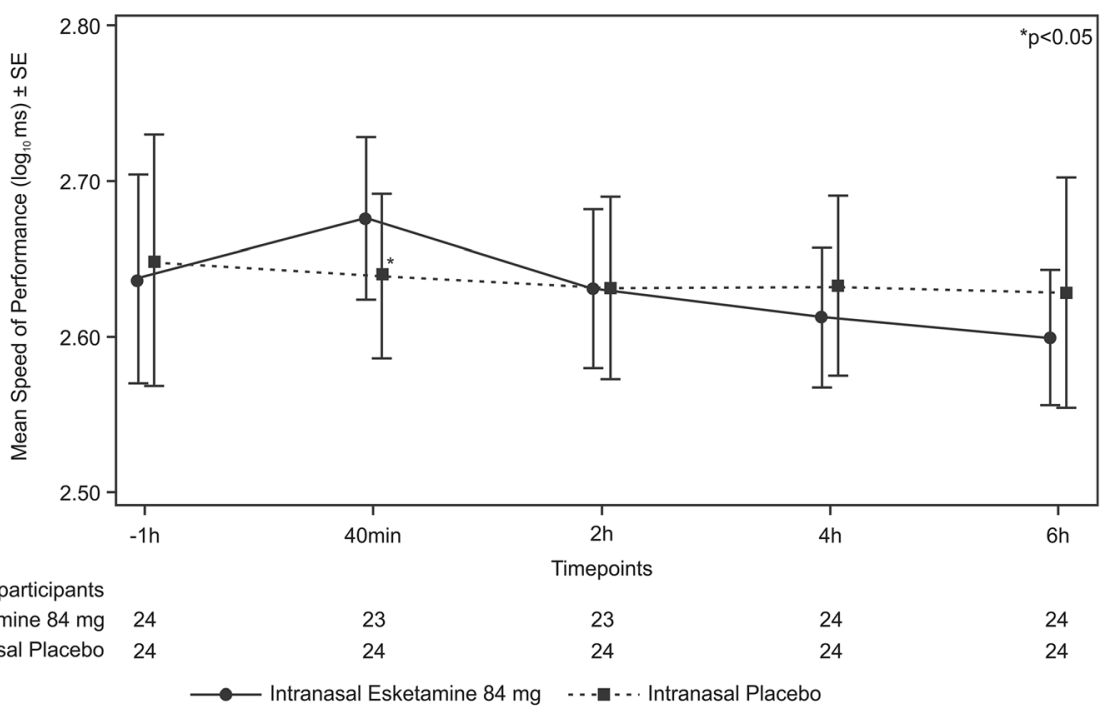

C

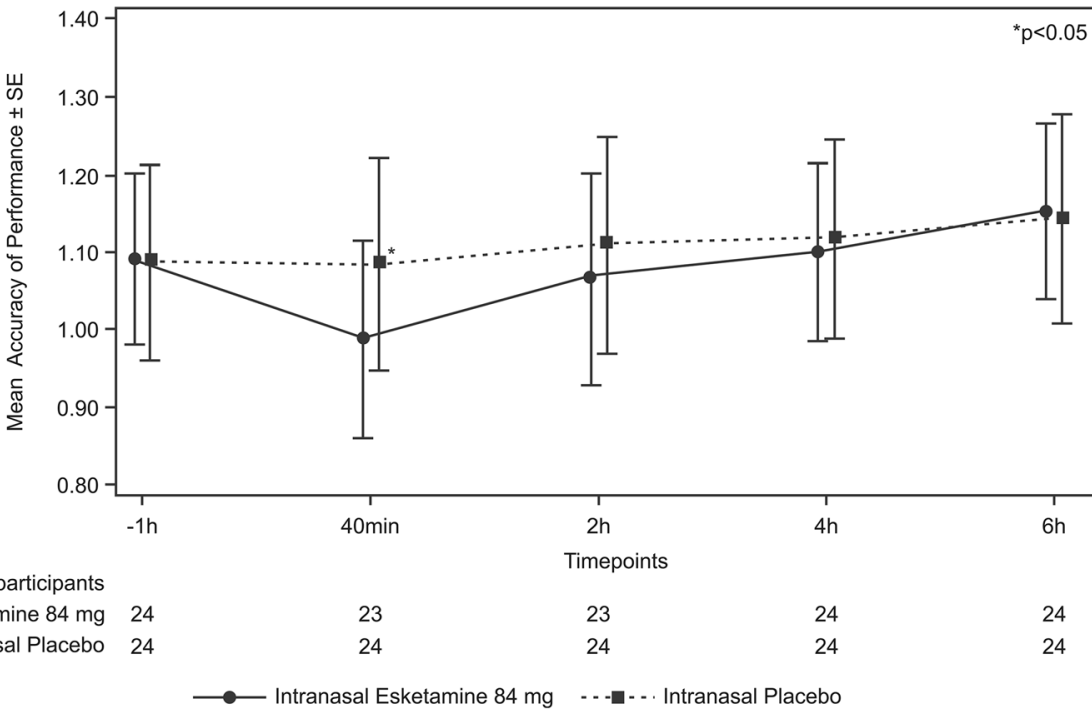

Fig. 2 Cognitive function measures mean plots $( \pm$ SE) for a Detection, b Identification, c One-Card Learning d One Back, e Groton Maze Learning Test (ITT Analysis Set) 
d
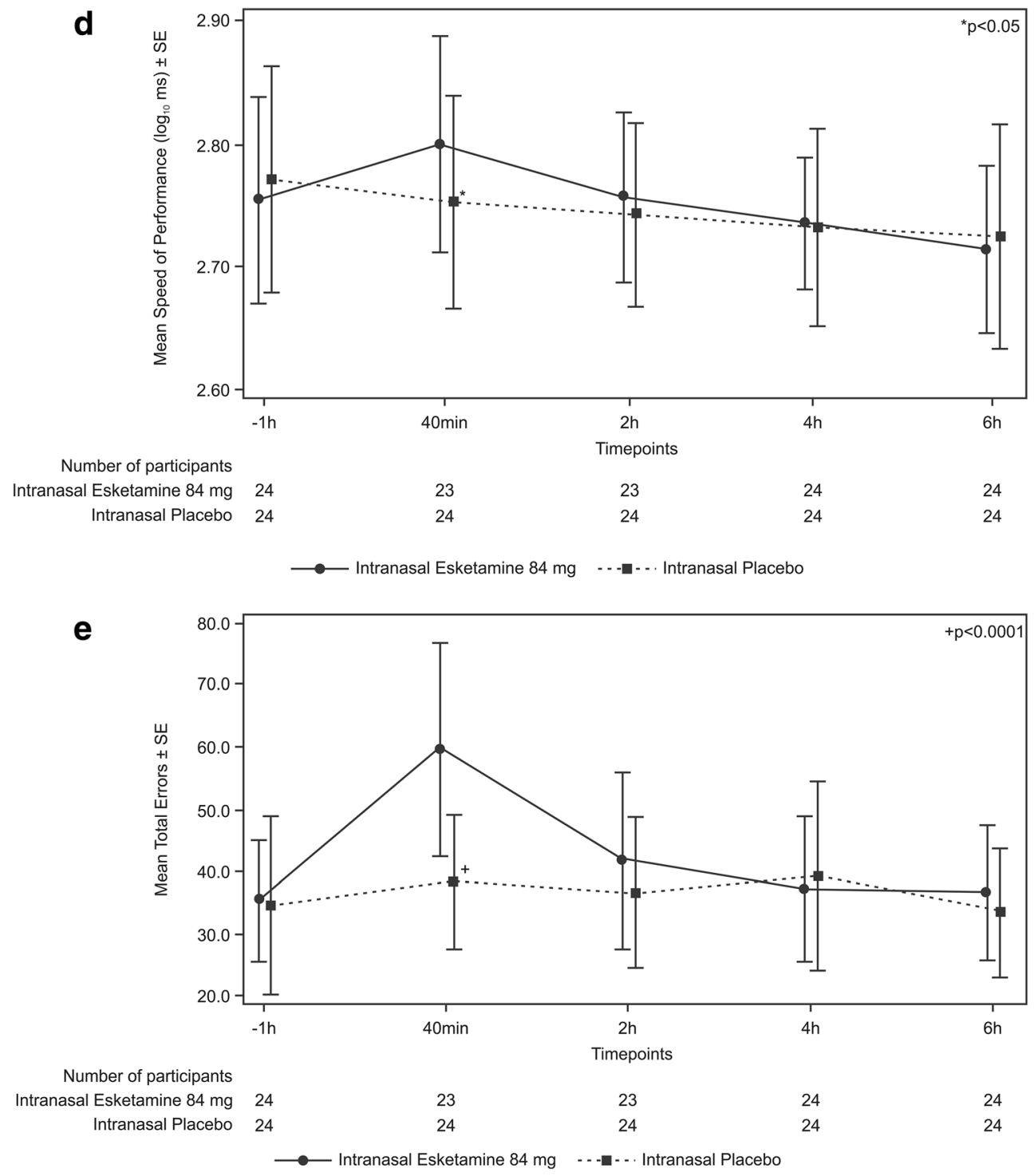

Fig. 2 (continued)

TEAEs, or TEAEs leading to discontinuation, occurred in this study.

The dissociative symptoms assessed using the CADSS and treatment-emergent psychotic symptoms assessed using the BPRS+ were reported in participants receiving intranasal esketamine, with transient increases at $40 \mathrm{~min}$ postdose as compared to placebo, returning to baseline by $2 \mathrm{~h}$ postdose (Fig. $4 \mathrm{a}, \mathrm{b}$ ). Following esketamine administration, more participants demonstrated a transient increase in sedation, as assessed using the MOAA/S, compared to placebo (esketamine: $n=6$; placebo: $n=1$ ) through $4 \mathrm{~h}$ postdose. No dissociative or psychotic symptom and no change in sedation was reported in participants receiving intranasal placebo at any time point. No post-baseline change in suicidal ideation or behavior was evident on the CSSR-S in participants from either group. Overall, no clinically significant effect on the laboratory parameters, vital signs, or electrocardiogram parameters was observed.

\section{Discussion}

This is the first clinical study to evaluate the effects of intranasal esketamine on cognitive functioning. In this exploratory study in healthy participants, administration of intranasal esketamine $84 \mathrm{mg}$ was associated with a transient decline in cognitive function, manifested either as slower performance time or greater error rates at $40 \mathrm{~min}$ postdosing as compared to intranasal placebo, but performance returned to levels comparable to placebo by $2 \mathrm{~h}$ postdose. No significant 
Table 3 Cognitive Functioning Tests: Comparisons of Screening vs Predoses (ITT Analysis Set)

\begin{tabular}{lcc}
\hline Tests & Screening & Predose Period 1 \\
\hline $\mathrm{N}$ & 24 & 24 \\
Detection & & \\
Mean (SD) & $2.40(0.051)$ & $2.41(0.062)$ \\
$p$ value & & 0.329 \\
Identification & & \\
Mean (SD) & $2.61(0.047)$ & $2.61(0.042)$ \\
$p$ value & & 0.482 \\
One-Card Learning & $1.09(0.125)$ & $1.08(0.120)$ \\
Mean (SD) & & 0.849 \\
$p$ value & & \\
One Back Memory & $2.76(0.072)$ & $2.76(0.086)$ \\
Mean (SD) & & 0.697 \\
$p$ value & & $37.00(14.200)$ \\
Groton Maze Learning Test & $38.42(9.117)$ & 0.567 \\
Mean (SD) & & \\
$p$ value & & \\
\hline$p$ alue-predosevs & & \\
\end{tabular}

$p$ value - predose vs screening

Detection - speed of performance ( $\log 10 \mathrm{~ms})$, Identification - speed of performance (Log10 ms), One-Card learning - accuracy of performance, One Back memory - speed of performance ( $\log 10 \mathrm{~ms})$, Groton Maze learning test - total numbers of errors, $\mathrm{ms}$ - milliseconds

${ }^{a} p$ values (2-sided with level of significance of 5\%) and CIs (2-sided) are based on paired t-test

difference between intranasal esketamine and placebo was observed at the 2-, 4-, and 6-h timepoints in the LS mean values for any of the five $\operatorname{Cogstate}{ }^{\circledR}$ tests. The transient reductions in cognitive function in participants receiving intranasal esketamine were associated with early postdose sedation, as assessed by the KSS and MOAA/S, and greater levels of effort required to complete the Cogstate ${ }^{\circledR}$ computerized test battery, as assessed using the Mental Effort Scale. The increases in sleepiness (at $40 \mathrm{~min}$ and $2 \mathrm{~h}$ postdose) and the mental effort required at $40 \mathrm{~min}$ post esketamine administration returned to levels comparable to placebo by 4 and $2 \mathrm{~h}$ postdose for mental effort (Fig. 2).

The participant-level data were examined posthoc to assess whether any individuals showed outlying values suggestive of longer-lasting effects. This assessment revealed that some participants' performance on cognitive tests had not returned to predose levels based on RCI criteria at $6 \mathrm{~h}$ post esketamine or longer; however, there were also participants whose cognitive test performance had not returned to predose levels at $6 \mathrm{~h}$ post placebo. Some participants continued to exhibit performance changes versus predose levels on one or more cognitive tests for up to $10 \mathrm{~h}$ postdose after esketamine or placebo, and these participant level data were most remarkable for the relatively larger number of participants whose performance appeared improved relative to baseline following esketamine $(n=10)$ versus after placebo $(n=4)$. While the potential contribution of fatigue or practice effects to these outlying values remains unclear, the apparent numerical difference between conditions in the numbers of participants showing improved performance at $10 \mathrm{~h}$ postdose merits further investigation, particularly in light of preclinical evidence in rodents that a single administration of ketamine alters synaptic plasticity in the hippocampus and medial prefrontal cortex (Kavalali and Monteggia 2012; Duman et al. 2016). Further discussion of participants meeting the RCI criterion for testing beyond $6 \mathrm{~h}$ postdose is provided in the Online Resource.

Performance on Detection, Identification, and Groton Maze Learning tests at period 2, 2 predose differed from screening, given that Detection and Identification scores declined at period 2 predose but Groton Maze improved, this is not likely a learning effect. The change from screening to period 2 predose was less than $1 \mathrm{SD}$ (based on Cogstate test norms) for each test. The differences may reflect minor variability in cognitive status of some subjects (e.g., perhaps related to changes in sleep, or mild health ailments). It should also be considered that subjects' period 1 experience in the study may have influenced anticipation/expectations about period 2. Several recent published reviews of studies of intravenous ketamine efficacy in MDD have highlighted that the side effects of ketamine may compromise blinding of subjects and investigators/raters, thus introducing potential bias (example, Newport et al. 2015). However, in contrast to self- or clinician ratings of mood/symptoms, which can be subjective, the present study measured cognitive performance via objective cognitive tests; all were computer administered and scored. The present study did not assess blinding efficacy, and while it cannot be assured that cognitive performance was unaffected by potential unblinding, as noted, there was no uniform directionality to the cognitive performance differences that were observed at period 2 predose versus screening. It will be important that procedures to minimize unblinding are optimized in efficacy trials of intranasal esketamine treatment for MDD, especially in regard to clinician ratings. The effect of intranasal esketamine on increased sleepiness assessed using KSS was more sustained relative to the effects on cognition, returning to near baseline levels by $4 \mathrm{~h}$ postdose.

Ketamine has been shown to exert a rapid onset of antidepressant effect in patients with TRD (Machado-Vieira et al. 2009; Murrough et al. 2013a, b; Newport et al. 2015; Yang et al. 2015). However, evidence shows that 
Fig. 3 Secondary cognitive function measures mean plots $( \pm$ SE) for a Mental Effort Scale and b Karolinska Sleepiness Scale (ITT Analysis Set) a

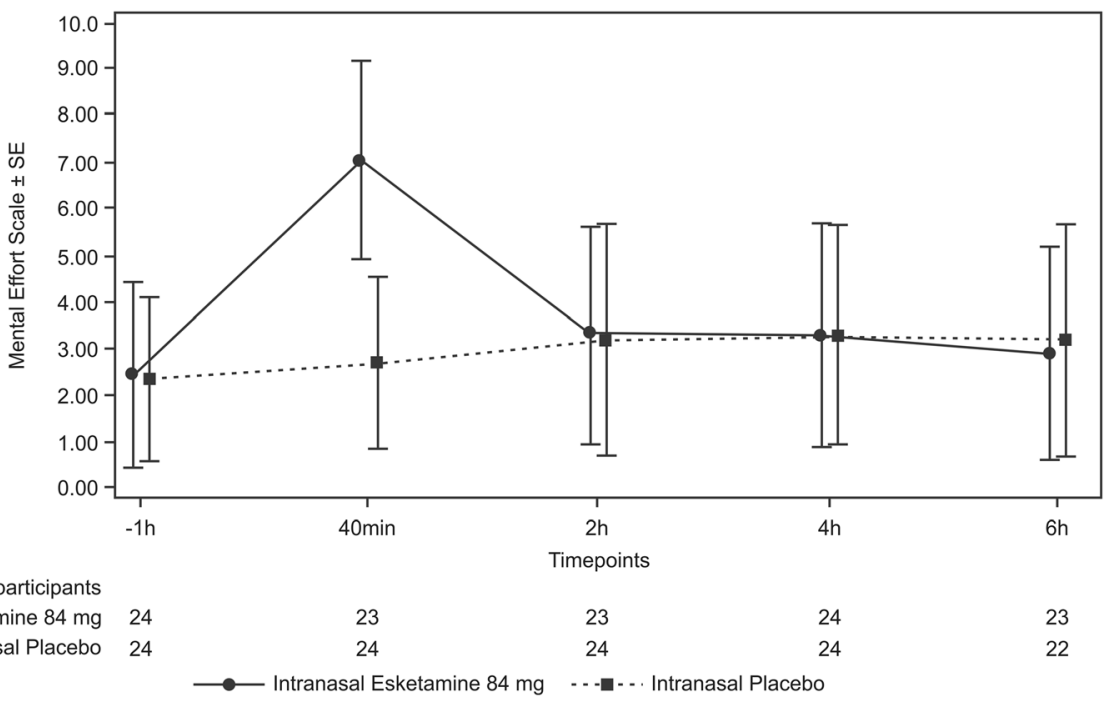

b

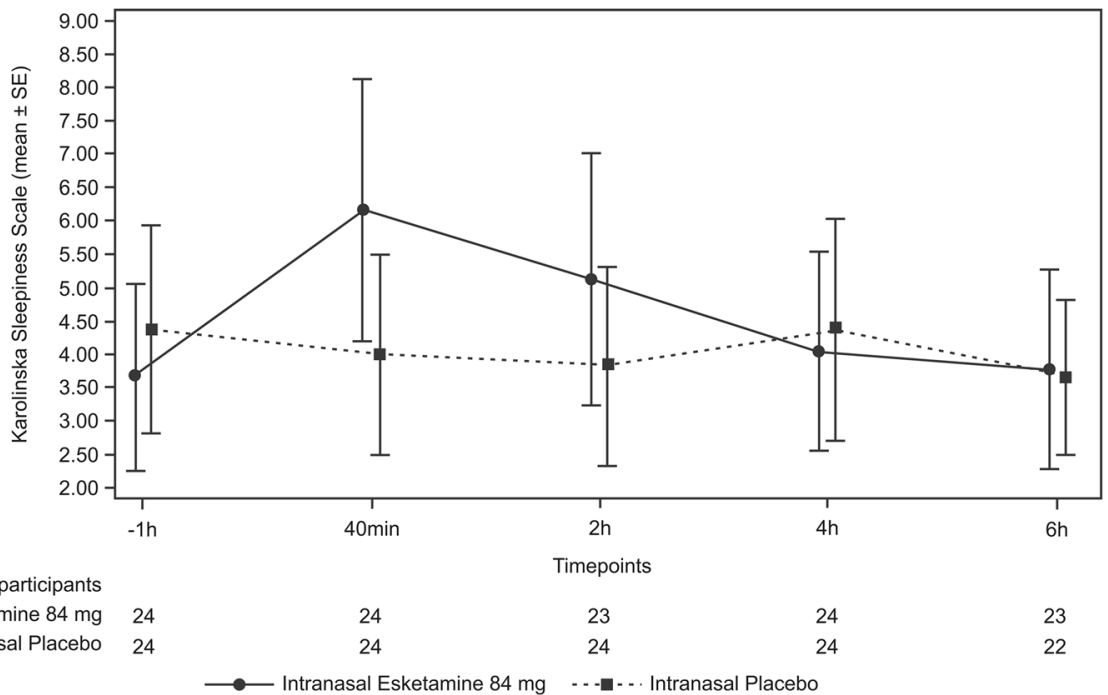

ketamine also is associated with acute perceptual and cognitive disturbances following drug administration in healthy participants as well as in patients with mood disorders (Krystal et al. 2005; Perry et al. 2007; Murrough et al. 2013a, b). Frequent abuse of high doses of ketamine can also lead to persistent neurocognitive impairment (Morgan and Curran 2006; Morgan et al. 2009).

In controlled studies of TRD patients, Murrough et al. previously reported circumscribed memory impairment immediately following a single ketamine dose $(0.5 \mathrm{mg} / \mathrm{kg})$ administered as a slow infusion over $40 \mathrm{~min}$ (Murrough et al. 2014). In contrast, two studies which explored the neurocognitive effects of up to six ketamine infusions in patients with TRD (with unipolar or bipolar depression) demonstrated no impairment (Diamond et al. 2014; Shiroma et al. 2014). Shiroma et al. (Shiroma et al. 2014) demonstrated that serial infusions of ketamine in TRD were not associated with cognitive decline over 4 weeks. This was consistent with the study by Diamond et al. (2014), where no memory deficits were noted after repeated ketamine administration, measured 4-7 days as well as 12 and 26 weeks after the final infusion. In the study by Shiroma et al. (2014) as well as in the recent study by Murrough et al. (2015), neurocognitive performance improved following treatment with intravenous ketamine. However, the studies were limited by small sample sizes, thus restricting a conclusive analysis of the relationship between cognitive effects and ketamine's antidepressant activity. Also, only the report by Murrough et al. (2013a, b) assessed ketamine effects on cognitive function immediately after a single administration of intravenous ketamine. In the other studies, cognitive assessment was conducted days/weeks following a course of 
Table 4 Treatment-emergent adverse events in at least $10 \%$ of participants in any treatment group (safety analysis set)

\begin{tabular}{lcc}
\hline & $\begin{array}{l}\text { Esketamine 84 mg } \\
N=24\end{array}$ & $\begin{array}{c}\text { Placebo } \\
N=24\end{array}$ \\
\hline Participants with 1 or more TEAEs & $24(100)$ & $9(38)$ \\
Dizziness & $16(67)$ & $1(4)$ \\
Headache & $5(21)$ & $3(13)$ \\
Disturbance in attention & $7(29)$ & 0 \\
Somnolence & $6(25)$ & $1(4)$ \\
Dysgeusia & $3(13)$ & $1(4)$ \\
Hypoaesthesia & $4(17)$ & 0 \\
Paraesthesia & $3(13)$ & $1(4)$ \\
Fatigue & $7(29)$ & 0 \\
Feeling abnormal & $6(25)$ & 0 \\
Feeling drunk & $4(17)$ & 0 \\
Feeling hot & $4(17)$ & 0 \\
Nausea & $9(38)$ & 0 \\
Vomiting & $5(21)$ & 0 \\
Vision blurred & $4(17)$ & 0 \\
Hallucination, visual & $3(13)$ & 0 \\
\hline
\end{tabular}

Values denoted as $n(\%)$. Percentages calculated with the number of participants in each group as denominator

TEAE treatment-emergent adverse events

ketamine infusions; cognitive effects in the period 4060 min post ketamine administration were not assessed. In the current study, the adverse cognitive effects experienced by these healthy participants were of short duration and resolved by $2 \mathrm{~h}$ postdose, returning to levels comparable to those obtained with placebo (Fig. 2). There has been no previous published report of the effects of intranasal esketamine on cognitive function in patients with MDD or on repetitive measurement to assess the time course and resolution of cognitive changes.

Our observations were substantiated using the Mental Effort Scale, an assessment of the level of effort needed to complete the test battery. Reductions in cognitive performance at $40 \mathrm{~min}$ postdose in participants receiving esketamine $84 \mathrm{mg}$ were associated with a greater level of effort required to complete the test battery. The effect of intranasal esketamine on increased sleepiness, compared to placebo, as assessed by the KSS, was more sustained relative to the effects on cognition, returning to near baseline levels by $4 \mathrm{~h}$ postdose. However, repeated use of some drugs may lead to fewer side effects and increased tolerance over time, allowing patients to function at normal, placebo-comparable levels (Verster et al. 2015). It is yet to be seen if the effects of intranasal esketamine on reduced cognitive performance and increased sleepiness may attenuate with more consistent drug use in patients.

Consistent with previous observations obtained during intravenous infusion of esketamine in participants with TRD (Singh et al. 2016), most TEAEs observed following intranasal esketamine were rated mild or moderate in severity. All TEAEs resolved by the end of the study, and no severe or serious $\mathrm{AE}$ or deaths was reported. No treatment-emergent abnormal laboratory results or electrocardiogram values were reported in this study. The single intranasal dose of esketamine $84 \mathrm{mg}$ showed no medically significant safety concerns in healthy participants. This safety profile was consistent with that observed in studies of TRD that involved intravenous ketamine or esketamine administration (aan het Rot et al. 2010; Singh et al. 2016).

The significance of our findings should be evaluated in the scope of study limitations. The study examined cognitive effects of only a single dose of intranasal esketamine, in a small sample of healthy volunteers. While the results contribute to the understanding of acute intranasal esketamine effects, this exploratory study is neither designed nor sufficient to enable conclusions about cognitive safety of intranasal esketamine. Rather, such conclusions will, at a minimum, require data from large clinical trials in patients with MDD in which the cognitive effects of intranasal esketamine are evaluated, including cognitive effects during and following both acute and maintenance treatment. A strength of the study design was the use of the Cogstate ${ }^{\circledR}$ Battery, which has been validated against traditional neuropsychological tests (Maruff et al. 2009; Pietrzak et al. 2009) shown to have limited practice effects at brief test-retest intervals (Collie et al. 2003), and is sensitive to effects of various drugs on cognitive performance including ETOH and benzodiazepines (Maruff et al. 2005; Snyder et al. 2005).

Overall, the results demonstrate that a single dose of intranasal esketamine $84 \mathrm{mg}$ was associated with a decline in cognitive function compared to placebo at $40 \mathrm{~min}$ postdose, which returned to levels comparable to placebo by $2 \mathrm{~h}$ postdose. The reductions in cognitive performance were associated with a greater level of effort required to complete the test battery. Sedation was longer lasting insofar as the drug versus placebo difference in KSS scores remained statistically significant at $2 \mathrm{~h}$, but no significant difference in KSS scores was evident between conditions by $4 \mathrm{~h}$ postdose.

Finally, the observation that the number of participants showing improved performance at $10 \mathrm{~h}$ postdose relative to baseline was larger following esketamine than following placebo (10 versus 4 , respectively) merits investigation in future studies designed to assess cognitive-enhancing as well as cognitive-impairing effects, particularly in light of preclinical evidence that ketamine administration increases synaptic 
Fig. 4 Total scores over time [mean (SD)] for a Brief

Psychiatric Rating Scale and $\mathbf{b}$

Clinician-Administered

Dissociative States Scale (Safety

Analysis Set)

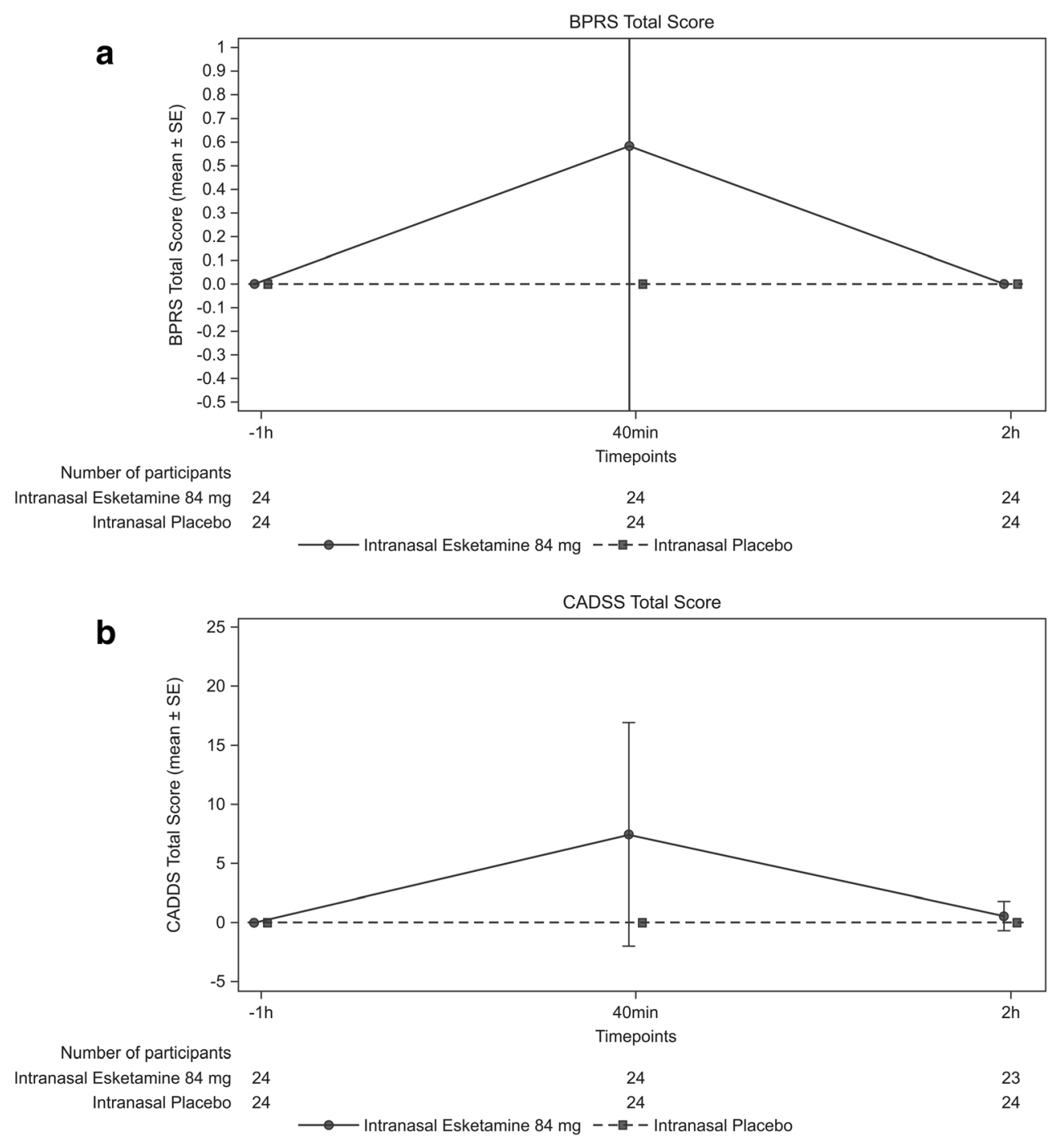

plasticity in the hippocampus and medial prefrontal cortex in rodent stress models (Kavalali and Monteggia 2012, Duman et al. 2016). Further clinical testing also is needed to evaluate the potential differences in esketamine's effects on cognition between acute administration versus repeated administration.

Acknowledgements Dr. Shalini Nair and Dr. Shivangi Gupta (SIRO Clinpharm) provided writing assistance and Dr. Harry Ma (Janssen Research \& Development, LLC) provided additional editorial support for the development of this manuscript. The authors also thank all the participants and investigators without whom the study would not have been accomplished.

Study support This study was funded by Janssen Research \& Development, LLC.

Author contributions Drs. Morrison, Fedgchin, Singh, Zannikos, and Drevets were involved in the study design and contributed towards data and sample analyses. Drs. Peter van der Ark, Joop Van Gerven, Rob Zuiker, Kyoung Soo Lim, and Ewa Wajs were involved in study execution. Dr. Liwen Xi was the project statistician who contributed to the study design and data analysis. All authors contributed to the data interpretation for the results.

All the authors met ICMJE criteria and all those who fulfilled those criteria are listed as authors. All authors had access to the study data, provided direction and comments on the manuscript, made the final decision about where to publish these data, and approved submission to the journal.

Compliance with ethical standards The Independent Ethics Committee or Institutional Review Board approved the protocol. The study was conducted in accordance with the ethical principles that have their origin in the Declaration of Helsinki, consistent Good Clinical Practices, and applicable regulatory requirements. All participants provided written informed consent to participate in the study.

Conflict of interest Drs. Morrison, Fedgchin, Singh, van der Ark, Wajs, $\mathrm{Xi}$, Zannikos, and Drevets are employees of Janssen Research \& 
Development and hold stock in the company. The study site received a research grant from Janssen Research \& Development.

Open Access This article is distributed under the terms of the Creative Commons Attribution 4.0 International License (http:// creativecommons.org/licenses/by/4.0/), which permits unrestricted use, distribution, and reproduction in any medium, provided you give appropriate credit to the original author(s) and the source, provide a link to the Creative Commons license, and indicate if changes were made.

\section{References}

aan het Rot M, Collins KA, Murrough JW, Perez AM, Reich DL, Charney DS, Mathew SJ (2010) Safety and efficacy of repeateddose intravenous ketamine for treatment-resistant depression. Biol Psychiatry 67(2):139-145. https://doi.org/10.1016/j.biopsych.2009. 08.038

Andrade C (2015) Intranasal drug delivery in neuropsychiatry: focus on intranasal ketamine for refractory depression. J Clin Psychiatry 76 : 628-631

Bitter C (2011) Transmucosal nasal drug delivery: pharmacokinetics and pharmacodynamics of nasally applied esketamine. Dissertation, University of Basel

Collie A, Maruff P, McStephen M, Darby D (2003) Psychometric issues associated with computerised neuropsychological assessment of concussed athletes. Br J Sports Med 37(6):556-559. https://doi. org/10.1136/bjsm.37.6.556

Daly E, Singh J, Fedgchin M, Cooper K, Lim P, Shelton RC, Thase ME, Winokur A, Van Nueten L, Manji H, Drevets WC (2017) Efficacy and safety of intranasal esketamine in treatment-resistant depression: results of a double-blind, doubly-randomized, placebo-controlled study. Am J Psychiatry. In press

Diamond PR, Farmery AD, Atkinson S, Haldar J, Williams N, Cowen PJ, Geddes JR, McShane R (2014) Ketamine infusions for treatment resistant depression: a series of 28 patients treated weekly or twice weekly in an ECT clinic. J Psychopharmacol 28(6):536-544. https:// doi.org/10.1177/0269881114527361

Diaz JH (1997) Intranasal ketamine preinduction of paediatric outpatients. Paediatr Anaesth 7(4):273-278. https://doi.org/10.1046/j. 1460-9592.1997.d01-93.x

Duman RS, Aghajanian GK, Sanacora G, Krystal JH (2016) Synaptic plasticity and depression: new insights from stress and rapid-acting antidepressants. Nat Med 22(3):238-249. https://doi.org/10.1038/ nm. 4050

Fact sheet (Reviewed April 2016). http://www.who.int/mediacentre/ factsheets/fs369/en/ Accessed date 23 August 2017

Himmelseher S, Pfenninger E (1998) The clinical use of S-(+)-ketaminea determination of its place. Anasthesiol Intensivmed Notfallmed Schmerzther 33(12):764-770. https://doi.org/10.1055/s-2007994851

Kavalali ET, Monteggia LM (2012) Synaptic mechanisms underlying rapid antidepressant action of ketamine. Am J Psychiatry 169(11): 1150-1156. https://doi.org/10.1176/appi.ajp.2012.12040531

Krystal JH, Perry EB Jr, Gueorguieva R, Belger A, Madonick SH, AbiDargham A, Cooper TB, Macdougall L, Abi-Saab W, D'Souza DC (2005) Comparative and interactive human psychopharmacologic effects of ketamine and amphetamine: implications for glutamatergic and dopaminergic model psychoses and cognitive function. Arch Gen Psychiatry 62(9):985-994. https://doi.org/10.1001/archpsyc. 62.9.985

Louon A, Reddy VG (1994) Nasal midazolam and ketamine for paediatric sedation during computerised tomography. Acta Anaesthesiol
Scand 38(3):259-261. https://doi.org/10.1111/j.1399-6576.1994. tb03885.x

Machado-Vieira R, Salvadore G, Diazgranados N, Zarate CA Jr (2009) Ketamine and the next generation of antidepressants with a rapid onset of action. Pharmacol Ther 123(2):143-150. https://doi.org/10. 1016/j.pharmthera.2009.02.010

Maruff P, Falleti MG, Collie A, Darby D, McStephen M (2005) Fatiguerelated impairment in the speed, accuracy and variability of psychomotor performance: comparison with blood alcohol levels. J Sleep Res 14(1):21-27. https://doi.org/10.1111/j.1365-2869.2004.00438.x

Maruff P, Thomas E, Cysique L, Brew B, Collie A, Snyder P, Pietrzak RH (2009) Validity of the CogState brief battery: relationship to standardized tests and sensitivity to cognitive impairment in mild traumatic brain injury, schizophrenia, and AIDS dementia complex. Arch Clin Neuropsychol 24(2):165-178. https://doi.org/10.1093/ $\operatorname{arclin} / \mathrm{acp} 010$

Mathew SJ, Murrough JW, aan het Rot M, Collins KA, Reich DL, Charney DS (2010) Riluzole for relapse prevention following intravenous ketamine in treatment-resistant depression: a pilot randomized, placebo-controlled continuation trial. Int J Neuropsychopharmacol 13(1):71-82. https://doi.org/10.1017/ S1461145709000169

McIntyre RS, Lophaven S, Olsen CK (2014) A randomized, doubleblind, placebo-controlled study of vortioxetine on cognitive function in depressed adults. Int J Neuropsychopharmacol 17(10):15571567. https://doi.org/10.1017/S1461145714000546

Morgan CJ, Curran HV (2006) Acute and chronic effects of ketamine upon human memory: a review. Psychopharmacology 188(4):408 424. https://doi.org/10.1007/s00213-006-0572-3

Morgan CJ, Muetzelfeldt L, Curran HV (2009) Ketamine use, cognition and psychological wellbeing: a comparison of frequent, infrequent and ex-users with polydrug and non-using controls. Addiction 104(1):77-87. https://doi.org/10.1111/j.1360-0443.2008.02394.x

Morgan CJ, Muetzelfeldt L, Curran HV (2010) Consequences of chronic ketamine self-administration upon neurocognitive function and psychological wellbeing: a 1-year longitudinal study. Addiction 105(1): 121-133. https://doi.org/10.1111/j.1360-0443.2009.02761.x

Murrough JW, Iosifescu DV, Chang LC, Al Jurdi RK, Green CE, Perez AM, Iqbal S, Pillemer S, Foulkes A, Shah A, Charney DS, Mathew SJ (2013a) Antidepressant efficacy of ketamine in treatmentresistant major depression: a two-site randomized controlled trial. Am J Psychiatry 170(10):1134-1142. https://doi.org/10.1176/appi. ajp.2013.13030392

Murrough JW, Perez AM, Pillemer S, Stern J, Parides MK, aan het Rot M, Collins KA, Mathew SJ, Charney DS, Iosifescu DV (2013b) Rapid and longer-term antidepressant effects of repeated ketamine infusions in treatment-resistant major depression. Biol Psychiatry 74(4):250-256. https://doi.org/10.1016/j.biopsych.2012.06.022

Murrough JW, Wan LB, Iacoviello B, Collins KA, Solon C, Glicksberg B, Perez AM, Mathew SJ, Charney DS, Iosifescu DV, Burdick KE (2014) Neurocognitive effects of ketamine in treatment-resistant major depression: association with antidepressant response. Psychopharmacology 231(3):481-488. https://doi.org/10.1007/ s00213-013-3255-x

Murrough JW, Burdick KE, Levitch CF, Perez AM, Brallier JW, Chang LC, Foulkes A, Charney DS, Mathew SJ, Iosifescu DV (2015) Neurocognitive effects of ketamine and association with antidepressant response in individuals with treatment-resistant depression: a randomized controlled trial. Neuropsychopharmacology 40(5): 1084-1090. https://doi.org/10.1038/npp.2014.298

Narendran R, Frankle WG, Keefe R, Gil R, Martinez D, Slifstein M, Kegeles LS, Talbot PS, Huang Y, Hwang DR, Khenissi L, Cooper TB, Laruelle M, Abi-Dargham A (2005) Altered prefrontal dopaminergic function in chronic recreational ketamine users. Am J Psychiatry 162(12):2352-2359. https://doi.org/10.1176/appi.ajp. 162.12 .2352 
Newport DJ, Carpenter LL, McDonald WM, Potash JB, Tohen M, Nemeroff CB, A. P. A. C. o. R. T. F. o. N. Biomarkers and Treatments (2015) Ketamine and other NMDA antagonists: early clinical trials and possible mechanisms in depression. Am J Psychiatry 172(10):950-966. https://doi.org/10.1176/appi.ajp. 2015.15040465

Olver JS, Ignatiadis S, Maruff P, Burrows GD, Norman TR (2008) Quetiapine augmentation in depressed patients with partial response to antidepressants. Hum Psychopharmacol 23(8):653-660. https:// doi.org/10.1002/hup. 970

Perry EB Jr, Cramer JA, Cho HS, Petrakis IL, Karper LP, Genovese A, O’Donnell E, Krystal JH, D'Souza DC, Yale G Ketamine Study (2007) Psychiatric safety of ketamine in psychopharmacology research. Psychopharmacology 192:253-260

Pietrzak RH, Olver J, Norman T, Piskulic D, Maruff P, Snyder PJ (2009) A comparison of the CogState Schizophrenia Battery and the Measurement and Treatment Research to Improve Cognition in Schizophrenia (MATRICS) Battery in assessing cognitive impairment in chronic schizophrenia. J Clin Exp Neuropsychol 31(7):848859. https://doi.org/10.1080/13803390802592458

Shiroma PR, Albott CS, Johns B, Thuras P, Wels J, Lim KO (2014) Neurocognitive performance and serial intravenous subanesthetic ketamine in treatment-resistant depression. Int J Neuropsychopharmacol 17(11):1805-1813. https://doi.org/10. 1017/S1461145714001011

Singh JB, Fedgchin M, Daly E, Xi L, Melman C, De Bruecker G, Tadic A, Sienaert P, Wiegand F, Manji H, Drevets WC (2016) Intravenous esketamine in adult treatment-resistant depression: a double-blind, double-randomization, placebo-controlled study. Biol Psychiatry 80(6):424-431. https://doi.org/10.1016/j.biopsych.2015.10.018

Snyder PJ, Werth J, Giordani B, Caveney AF, Feltner D, Maruff P (2005) A method for determining the magnitude of change across different cognitive functions in clinical trials: the effects of acute administration of two different doses alprazolam. Hum Psychopharmacol 20(4):263-273. https://doi.org/10.1002/hup.692

Verster JC, van de Loo AJ, Roth T (2015) Mirtazapine as positive control drug in studies examining the effects of antidepressants on driving ability. Eur J Pharmacol 753:252-256. https://doi.org/10.1016/j. ejphar.2014.10.032

Weber F, Wulf H, El Saeidi G (2003) Premedication with nasal sketamine and midazolam provides good conditions for induction of anesthesia in preschool children. Can J Anaesth 50(5):470-475. https://doi.org/10.1007/BF03021058

Weksler N, Ovadia L, Muati G, Stav A (1993) Nasal ketamine for paediatric premedication. Can J Anaesth 40(2):119-121. https://doi.org/ 10.1007/BF03011307

Yanagihara Y, Ohtani M, Kariya S, Uchino K, Hiraishi T, Ashizawa N, Aoyama T, Yamamura Y, Yamada Y, Iga T (2003) Plasma concentration profiles of ketamine and norketamine after administration of various ketamine preparations to healthy Japanese volunteers. Biopharm Drug Dispos 24(1):37-43. https://doi.org/10.1002/bdd. 336

Yang C, Shirayama Y, Zhang JC, Ren Q, Yao W, Ma M, Dong C, Hashimoto K (2015) R-ketamine: a rapid-onset and sustained antidepressant without psychotomimetic side effects. Transl Psychiatry 5(9):e632. https://doi.org/10.1038/tp.2015.136

Yoshida T, Ishikawa M, Niitsu T, Nakazato M, Watanabe H, Shiraishi T, Shiina A, Hashimoto T, Kanahara N, Hasegawa T, Enohara M (2012) Decreased serum levels of mature brain-derived neurotrophic factor (BDNF), but not its precursor proBDNF, in patients with major depressive disorder. PLoS One 7(8):e42676. https://doi.org/ 10.1371/journal.pone.0042676

Zarate CA, Singh JB, Carlson PJ, Brutsche NE, Ameli R, Luckenbaugh DA, Charney DS, Manji HK (2006) A randomized trial of an Nmethyl-D-aspartate antagonist in treatment-resistant major depression. Arch Gen Psychiatry 63(8):856-864. https://doi.org/10.1001/ archpsyc.63.8.856 